\title{
Laser Surface Texturing to Realize Micro-grids on DLC Coating: Effect of Marking Speed, Power, and Loop Cycle
}

\author{
L. Giorleo ${ }^{1}(1) \cdot$ L. Montesano ${ }^{1}$. G. M. La Vecchia ${ }^{1}$
}

Received: 10 September 2019 / Revised: 6 December 2019 / Accepted: 17 February 2021 / Published online: 9 March 2021

(c) The Author(s) 2021

\begin{abstract}
In the present study, laser surface texturing was tested with the aim of improving the tribological properties of a diamond-like carbon (DLC) coating. Two experimental campaigns were designed to realize different micro-grids, and to study the effect of marking speed, laser power, and loop cycle. The grid profiles obtained were analyzed using a digital microscope and a laser probe system to measure the track cross section. At the end of the experiments, the authors identified a good-quality track obtained by imposing a marking speed of $300 \mathrm{~mm} / \mathrm{s}$, a power of $0.5 \mathrm{~W}$, and one loop cycle. For the identified condition, the presence of defects (such as cracks) on both the coated surface and at the substrate/coating interface was analyzed. Furthermore, the coating nanohardness, adhesion to the substrate, and wear behavior in dry condition were investigated. The results underline how laser texturing can improve the DLC wear behavior (wear tracks lower than $30 \%$ ) without considerably affecting the other tested coating properties.
\end{abstract}

Keywords Laser surface texturing $\cdot$ DLC coating $\cdot$ Wear behavior

\section{Introduction}

Diamond-like carbon (DLC) is the commonly used term for the hydrogenated form of diamond-like carbon (a-C:H), while nonhydrogenated carbon $(\mathrm{a}-\mathrm{C})$ is usually termed tetrahedral carbon ( $\mathrm{taC})$. The properties of both these coatings depend strongly on the hydrogen content and on the $\mathrm{sp}_{3} / \mathrm{sp}_{2}$ bond ratio, which in turn depend on the deposition process and its parameters. Basically, the DLC structure is an amorphous network composed of carbon and hydrogen linked with covalent and weak interlayer bonds, while the taC structure is a very rigid network, mainly composed of $\mathrm{sp}_{3}$ covalent bonds [1,2]. The principal use of DLC coatings is related to the hydrogenated form, because of its low friction coefficient against many different materials, such as steel [3], ceramics [4], and polymers having high wear resistance [5], and its chemical inertness for biomedical devices [6]. Moreover, DLC-positive mechanical properties can be tailored as a function of the deposition parameters, or by using metals or non-metals as dopant elements [7, 8]. In addition, DLC

$\triangle$ L. Giorleo

luca.giorleo@unibs.it

1 Department of Mechanical and Industrial Engineering, University of Brescia, Brescia, Italy coatings (as being wear resistant) have been widely studied on different substrates, from steel [9] and cobalt chromium alloy [10], to polymers such as polyetheretherketone (PEEK) [6] and polytetrafluoroethylene [11]. However, despite the aforementioned benefits, greater reduction in frictional loss is still an important issue to meet the requirements of highefficiency parts; therefore, advanced machining operations are needed to realize the surface pattern. In fact, the effect of different shape patterns such as dimples, grooves, and grids can be associated with several mechanisms: micro-hydrodynamic bearings that generate additional pressure to provide additional lift, lubricant micro-reservoirs to enhance lubricant retention, container of wear debris to avoid third-body abrasion, and reduction of the contact between surfaces in relative motion. The conventional technique used to machine coatings consists of many different steps that are realized with a mechanical tool. However, this requires great effort owing to the low removal rate, and a lack of performance is registered in the case of surfaces characterized by high hardness, limited accessibility of a part, micro-dimensions, or three-dimensional (3D) free-form surfaces.

In the last decade, laser surface texturing (LST) has been studied as a technology that can provide excellent control of the texture geometry, fast processing time, and low environmental impact $[12,13]$. It has been demonstrated how LST 
can remarkably enhance the tribological performances of textured surfaces in dry [14] or lubricated conditions [15]. Regarding the combination of an LST and DLC coating, Amanov et al. [16] fabricated micro-dimples on steel alloy surfaces and coated them with Si-DLC. The friction test results indicated that the textured Si-DLC coating resulted in a lower friction coefficient and less wear compared to untextured coatings. Shum et al. [17] tested the hydrophobicity, non-stickiness, and wear resistance of DLC coatings that were altered by introducing different surface textures by varying the dimple density from 0 to $30 \%$. They reported a $24 \%$ reduction in friction coefficient compared to a flat DLC surface. Dufils et al. [18] evaluated the mechanical and tribological performances of PEEK surfaces modified via LST combined with a DLC coating. They evidenced a coefficient of friction that decreased with increasing dimple density, probably because of wear debris trapping. Koszela et al. [19] investigated the combined effect of surface texturing and DLC coating on the functional properties of internal combustion engines. They found that cylinder texturing typically led to a decrease in resistance to sliding movement following an increase in the amount of lubricants in dimples. A decrease in the coefficient of friction caused an increase in power at a wide range of rotational speeds; it also resulted in a shift in engine characteristics towards higher rotational speeds. Shum et al. [20] focused their research on the effect of the dimple densities and diameters on the wear performance under oil lubrication conditions. The results showed that the DLC coatings with the appropriate dimple density $(10 \%)$ and diameter $(100 \mu \mathrm{m})$ demonstrated an obvious improvement in terms of the friction coefficient and wear rate compared with that of the un-textured DLC coatings. Arslan et al. [21] investigated the effectiveness of indirect laser textured DLC for cam/tappet contact in an engine; the results indicated that at a diameter of $50 \mu \mathrm{m}$ and $20 \%$ density enhanced the tribological performances. Liu et al. [22] used vacuum arc to prepare $\mathrm{Cr} / \mathrm{CrN} / \mathrm{DLC}$ films on different textured surfaces fabricated by femto-laser to analyze the influences of textures with different patterns, sizes, and orientations; finding improvement up to 50 times comparing DLC film as deposited with textured interface with $250 \mu \mathrm{m}$. He et al. [23] analyzed the effects of dimple densities and DLC phase transformation on the tribological behavior of titanium alloy under dry friction and liquid lubrication conditions. The results showed that DLC films with an appropriate dimple area density (44\%) were effective in enhancing the friction-reduction property of a titanium alloy substrate, owing to the entrapment of the wear particles in the dimples and to the dimple-induced graphitization during sliding motions, while the $24 \%$ textured specimen exhibited outstanding wear resistance.

It can be observed from the literature reviews that most of the studies available are based on dimple geometry realized on a DLC coating; in particular, the dimple density and diameter were tested to measure the wear or friction improvements. Recently, Lu et al. [24] evaluated the effect of typical patterns such as micro-dimples, micro-grooves, and micro-grids on the friction and wear properties of chromium alloy prepared by laser surface texturing. Experimental results showed that laser-textured surfaces significantly reduced the wear volume by up to $57 \%$, especially for surface patterns with micro-grids. Moreover, in most of the studies, the surface was first textured by a laser and then coated; however, this led to a modification of the substrate properties due to the interaction with the laser beam [17-24]. On the contrary, works where LST was designed after the coating realized texture that was thicker than the coating depth [16]. The main gap in the research is that most of the ongoing studies focus on the tribological characterization of textured DLC coating. Therefore, more information is required about the characterization of laser process parameters in the case of a thin texture on DLC-coated surfaces.

To increase the knowledge about the LST process on a DLC coating, in the present work, the authors studied the role of laser process parameters such as marking speed, power, and loop cycle to evaluate their effect on micro-grid features. The investigated surfaces were first coated with DLC and then textured by a laser beam. The selection of the aforementioned process parameters was carefully designed to avoid grids having a thickness greater than that of the DLC deposited. At the end of the experiments, the coating nanohardness and adhesion were measured on a selected texture to evaluate possible DLC damage such as cracks or delaminations caused by the laser process. Finally, the textured coating wear behavior was analyzed by using a pin-on disk equipment, and then compared with that of an untextured coating (a sample in an as-deposited condition).

\section{Materials and Methods}

\subsection{Material Characterization}

In this study, tool steel specimens $(30 \mathrm{~mm} \times 16 \mathrm{~mm} \times 5 \mathrm{~mm})$ were used as substrates. The chemical composition and mechanical properties of the steel used as a substrate are reported in Tables 1 and 2, respectively.

To guarantee good adhesion between the substrate and the coating, the authors polished the samples with abrasive papers with a grit size of up to $\mathrm{P} 1200$ before the deposition process. After polishing, the average surface roughness was $R_{a}=0.02 \mu \mathrm{m}$. The DLC coating (a-C:H) was deposited using the plasma-assisted chemical vapor deposition (PACVD) technique. According to industrial knowledge, two interlayers of chromium and chromium nitride were deposited by using the cathodic arc evaporation (CAE) technique in 
Table 1 Substrate chemical composition (wt.\%)

\begin{tabular}{ll}
\hline $\mathrm{C}$ & 0.425 \\
$\mathrm{~S}$ & 0.017 \\
$\mathrm{P}$ & 0.007 \\
$\mathrm{Mn}$ & 1.075 \\
$\mathrm{Cr}$ & 0.99 \\
$\mathrm{Ni}$ & 0.294 \\
$\mathrm{Mo}$ & 0.131 \\
$\mathrm{Cu}$ & 0.17 \\
$\mathrm{Si}$ & 0.634 \\
$\mathrm{Al}$ & 0.021 \\
\hline
\end{tabular}

Table 2 Substrate mechanical properties

\begin{tabular}{llll}
\hline $\begin{array}{l}\text { Yield strength } \\
\text { [MPa] }\end{array}$ & $\begin{array}{l}\text { Ultimate tensile } \\
\text { strength [MPa] }\end{array}$ & Elongation [\%] & $\begin{array}{l}\text { Rockwell C } \\
\text { hardness }\end{array}$ \\
\hline 884 & 1069 & 15 & 32 \\
\hline
\end{tabular}

Table 3 Deposition process parameters

\begin{tabular}{ll}
\hline DLC Deposition system & PACVD \\
\hline Interlayer deposition system & $\mathrm{CAE}$ \\
Chamber pressure [mbar] & $3 \times 10^{-3}$ \\
Target materials & $\mathrm{Cr}$ and liquid $\mathrm{SiH}_{4}$ \\
Substrate temperature $\left[{ }^{\circ} \mathrm{C}\right]$ & $\mathrm{Max} .250$ \\
Gases & $\mathrm{Ar}, \mathrm{H}, \mathrm{N}$, and $\mathrm{C}_{2} \mathrm{H}_{2}$ \\
Bias voltage $[\mathrm{V}]$ & $400-600$ \\
Time $[\mathrm{h}]$ & 4
\end{tabular}

the same system. The deposition parameters are reported in Table 3. A Calotest was performed to evaluate the coating thickness and to assess the presence of interlayers. A total coating thickness equal to $3.5 \pm 0.2 \mu \mathrm{m}$ was measured. In particular, it was composed of the thickness $(0.8 \pm 0.1 \mu \mathrm{m})$ of each interlayer and that of the DLC $(2.0 \pm 0.2 \mu \mathrm{m})$.

\subsection{Laser Surface Texturing Setup}

LST was performed on the coated samples by using a Nd:YOV4 laser (Lee Laser LEP-V20MGQ). The outgoing laser beam was collimated in a galvanometer scanner system to impose a remote control. The laser pattern (or filling strategy) was designed with the Laser Marking Studio (LMS) software integrated into the galvanometer scanner system. The fixed laser process parameters are summarized in Table 4.

The outgoing laser beam power distribution was measured with a Gentec Beamage-CCD12 beam profiler. The power density of the laser spot followed a Gaussian distribution, as can be seen in Fig. 1a.
Table 4 Fixed laser process parameters

\begin{tabular}{ll}
\hline Laser mode & CW \\
\hline Laser wavelength $[\mathrm{nm}]$ & 532 \\
Spot diameter $[\mathrm{mm}]$ & 0.06 \\
Focal distance $[\mathrm{mm}]$ & 160 \\
Laser pattern $[\mathrm{mm}]$ & square grid \\
Grid line spacing $[\mathrm{mm}]$ & 0.3 \\
\hline
\end{tabular}

To understand how the selected laser process parameters affect the track features and to define the optimized set to avoid a total DLC removal, the authors designed two different experimental campaigns: in the first experimental campaign, a $2^{3}$ factorial design as a function of laser marking speed, power, and loop was tested. Based on the results achieved, the second campaign focused on the marking speed effect. Four marking speed values were tested (from 100 to $400 \mathrm{~mm} / \mathrm{s}$ ), and three replicates of each campaign were performed to improve the robustness of the results. Table 5 shows the process parameters used in the experimental campaigns.

Qualitative and quantitative analyses of the track realized in both experimental campaigns were performed. To obtain the qualitative information about the track depth and width, the authors analyzed the laser tracks realized by using a 3D digital microscope (Hirox RH-2000). For the quantitative analysis, a laser probe system (Mitaka PF60) was used to acquire the laser track cross-section geometry. The mean depth and the related standard deviation were calculated. The standard deviation was considered to verify the bottom track quality. The maximum depth was also measured to exclude laser tracks having a depth higher than that of the DLC coating. Figure $1 b$ reports the applied method for the quantitative analyses of the laser track depth. To ensure a reliable statistical approach, the authors acquired 12 textured profiles for each experimental condition, in particular, 4 measures for each linear scan. Both experimental campaigns were analyzed by using a statistical approach.

\subsection{Micro-Grid Tribological Characterization Setup}

Based on the best setup found three micro-grid texture samples have been designed. A square geometry having length equal to $1,0.5$ and $0.25 \mathrm{~mm}$ was selected as texture. Table 6 summarized the texture parameter.

The obtained textured samples were compared with the sample in an as-deposited condition to analyze the performance in terms of coating morphology, nanohardness, adhesion, and wear resistance (texturing performance campaign). Before the cited tests the samples were firstly cleaned in ultrasonic bath with ethanol. Coating morphology analysis was performed with a scanning electron 

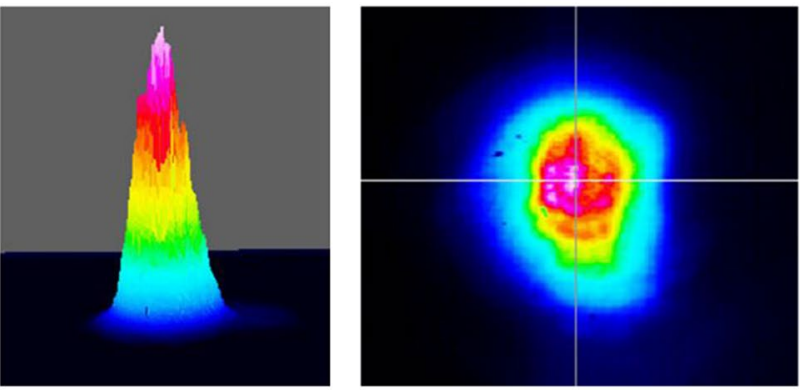

a

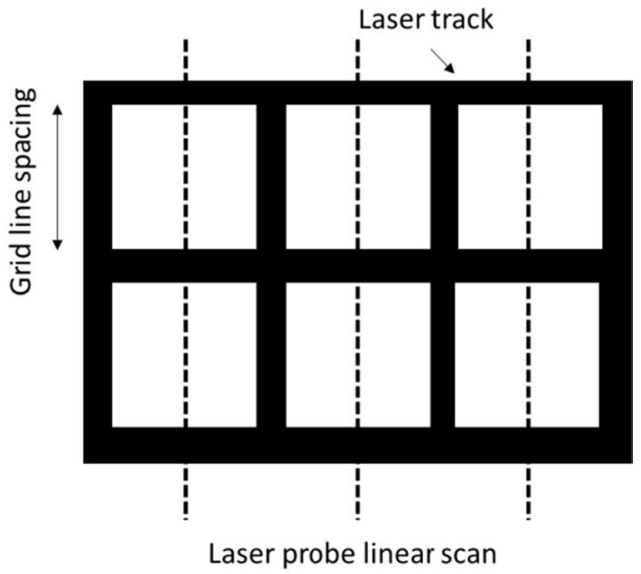

b

Fig. 1 Laser beam power distribution (a) and texture pattern realized (b)

Table 5 Setup of the experimental campaigns

\begin{tabular}{lll}
\hline Process parameter & $\begin{array}{l}\text { 1st Experimental } \\
\text { campaign }\end{array}$ & $\begin{array}{l}\text { 2nd } \\
\text { Experi- } \\
\text { mental } \\
\text { cam- } \\
\text { paign }\end{array}$ \\
\hline Laser loop cycle & 1,3 & 1 \\
Laser marking speed $[\mathrm{mm} / \mathrm{s}]$ & 100 and 400 & 100,200, \\
& & 300, \\
and \\
Laser power $[\mathrm{W}]$
\end{tabular}

Table 6 Setup of the lasered pattern for the micro grid tribological campaigns

\begin{tabular}{ll}
\hline Pattern design & Square \\
\hline Pattern spacing $[\mathrm{mm}]$ & $1,0.5,0.25$ \\
\hline
\end{tabular}

microscope (LEO EVO 40) equipped with an energy-dispersive spectroscopy (EDS) probe (Oxford Instruments). In particular, morphological and semi-quantitative chemical information about the textured surface was obtained, giving particular attention to the laser bottom track. The surface and cross section were analyzed to investigate the possible presence of defects or damages induced by the laser. Nanohardness tests were performed by using a Table Top Nanoindentation Tester (TTX-NHT, CSM Instruments).

Nanohardness measurements were performed according to the ISO 14,577 standard by using a Berkovich indenter with a maximum load equal to $3 \mathrm{mN}$, to fulfill the standard requirements in terms of indenter penetration depth. Twenty measurements were performed outside the laser tracks to obtain reliable statistical values.

Adhesion tests were carried out according to the ASTM C1624 standard by using a Rockwell C indenter with a tip radius of $200 \mu \mathrm{m}$, applying a linear load ramp with a maximum load of $50 \mathrm{~N}$, and a track $4 \mathrm{~mm}$ long. Three progressive critical loads were determined along the scratch: LC1 corresponding to the first lateral chipping, LC2 corresponding to the first delimitation, and LC3 relating to the total coating delamination from the substrate i.e. measure of coating adhesion. Three different scratches were made on the as-deposited and on the textured surfaces to obtain the mean and standard deviation values. In particular, scratch tracks were realized randomly on the textured surface (i.e., random orientation with respect to the laser texture). Tests were performed with a Revetest Xpress scratch tester (CSM Instruments).

The wear behavior was investigated with a THT tribometer (CSM Instruments) with a pin-on disk configuration according to the ASTM G99-04 standard. To avoid wear track contamination due to counterpart damage, the authors performed wear behavior tests using an alumina sphere (6 $\mathrm{mm}$ in diameter) as a counterpart, according to the literature procedures [1,2]. An applied load equal to $1 \mathrm{~N}$ was used to avoid plastic deformation in the substrate. The Hertzian pressure on the coating surface was calculated using the Hertz theory for a sphere-flat plan contact configuration. The calculated value of $550 \mathrm{MPa}$ was lower than the substrate yield stress (Table 2). All tests were run for a distance of $1000 \mathrm{~m}$ at a linear speed of $4 \mathrm{~cm} / \mathrm{s}$. The tests were performed in ambient air at a temperature of $25^{\circ} \mathrm{C} \pm 1^{\circ} \mathrm{C}$ and a relative humidity of $55 \% \pm 2 \%$. Before each test, the samples and counterparts were cleaned with alcohol to avoid any contamination. At the end of the wear tests, the wear tracks width was measured by means of the Hirox RH-2000 microscope 
to have an indication of the worn volume; measurement along the whole wear path was acquired and mean value and standard deviation were calculated. Moreover wear paths were analyzed using a scanning electron microscope to understand the effect of laser texture on the coating wear behavior more fully. Table 7 summarizes all the analyses conducted and the instruments used to perform them for all the experiments.

\section{Results and Discussion}

\subsection{Laser Surface Texturing Results}

Figure 2 reports the main results of the first experimental campaign in terms of texturing quality and laser track profile for different laser parameters. For clarity, each experiment was indexed with a code that classifies the experiment as a function of the laser parameters used, i.e., loop cycles, laser power, and marking speed, respectively. The code is reported in each textured track profile. To analyze the results, based on the Calotest results $(2.0 \pm 0.2 \mu \mathrm{m}$ of DLC), the authors established the following constraints to guarantee a correct texturing process:

- Maximum laser track depth not higher than $1.5 \mu \mathrm{m}$ to avoid a total DLC removal;

- Laser track width as narrow as possible to minimize the fraction of the machined surface.

Table 8 shows the data obtained from the measurements performed with the laser probe system. The laser energy that irradiates a single point $\left(E_{\mathrm{p}}\right)$ and the total energy $\left(E_{\mathrm{tot}}\right)$, evaluated as single point energy per loop, are also reported.

Comparing the microscope images and the results of laser analyses, one may be able to understand how the process parameters investigated affect the track cross section. In particular, from a qualitative point of view, it is possible to observe the following:
- How the laser power significantly affects the track width and, partially, the track depth. With regard to the bottom quality, no significant variation was observed.

- How an increase in the laser marking speed results in a reduction in the laser track depth. In regard to the bottom quality, an irregular profile was measured when the marking speed was equal to $100 \mathrm{~mm} / \mathrm{s}$ and the loop cycle was equal to 1 (Fig. 2a and c). The latter result can be attributed to the plasma shielding effect. As indicated in the literature, when the marking speed decreases, the interaction time between the beam laser and the irradiated surface increases; hence, $E_{\mathrm{p}}$ increases. This results in the generation of a plasma plume, which is responsible for the plasma shielding effect. The presence of plasma plume causes laser energy absorption and is a barrier to material evaporation [3]; therefore, there is no evaporation but a quick solidification of the plasma that induces a laser track bottom surface characterized by an irregular profile. This causes an increase in the average track depth, and a worsening of the bottom track quality. The track width is not strongly affected by the marking speed.

- How an increase in the loop cycle can be a good strategy to reduce the plasma shielding effect, as can be concluded by comparing Fig. 2c and d. An improvement in the track depth and width is also observed when the marking speed is lower and no plasma plume occurs (Fig. 2e vs. Figure 2f, and Fig. 2g vs. Figure $2 \mathrm{~h}$ ).

As a preliminary consideration, it is possible to assert that only the experiment with the code $1-0.50-400$ fully met the fixed target track depth lower than $1.5 \mu \mathrm{m}$ for both the mean and the maximum depth. However, the other three conditions presented an adequate mean track depth (3-0.50-400, 1-0.50-100, and 1-2.25-400).

For the quantitative analysis, an analysis of variance (ANOVA) test was performed on the track depth. Figure 3 shows the main results and the main effective plots of the investigated factors (power, marking speed, and loop cycle). The hypothesis of the homogeneity of the variance and the normality of the residuals was verified.
Table 7 Analyses conducted and instruments used in all the experiments

\begin{tabular}{llll}
\hline Analysis & Instrument & $\begin{array}{l}\text { Laser surface texturing } \\
\text { characterization }\end{array}$ & $\begin{array}{l}\text { Micro-grid tribo- } \\
\text { logical characteri- } \\
\text { zation }\end{array}$ \\
\hline 3D Digital microscopy & Hirox RH-2000 & $\checkmark$ & \\
Laser track profile & Mitaka PF60 & $\checkmark$ & $\checkmark$ \\
SEM & LEO EVO 40+EDS probe & & $\checkmark$ \\
Nanoindentation & TTX-NHT & & $\checkmark$ \\
Scratch test & Revetest Xpress & $\checkmark$ \\
Pin-on-disk test & THT Tribometer & \\
\hline
\end{tabular}




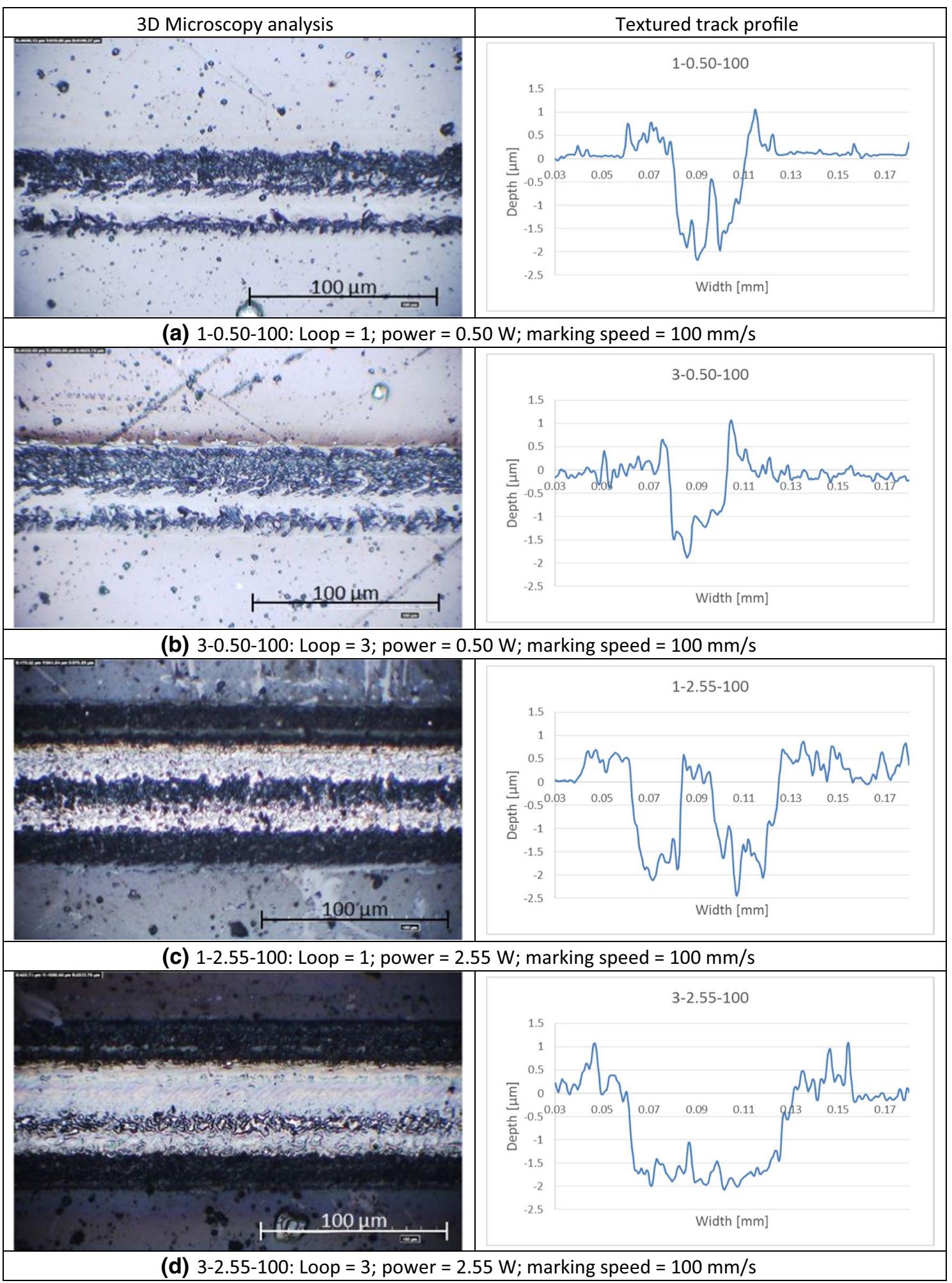

Fig. 2 Main results of the first experimental campaign

The ANOVA test results confirmed those previously reported in the qualitative analysis. As shown in Fig. 3a, the marking speed and loop cycle are strongly significant for the track depth $(P<0.05)$, while for the laser power a limit condition was found. The ANOVA results also highlighted that no interaction occurred between the process parameters 


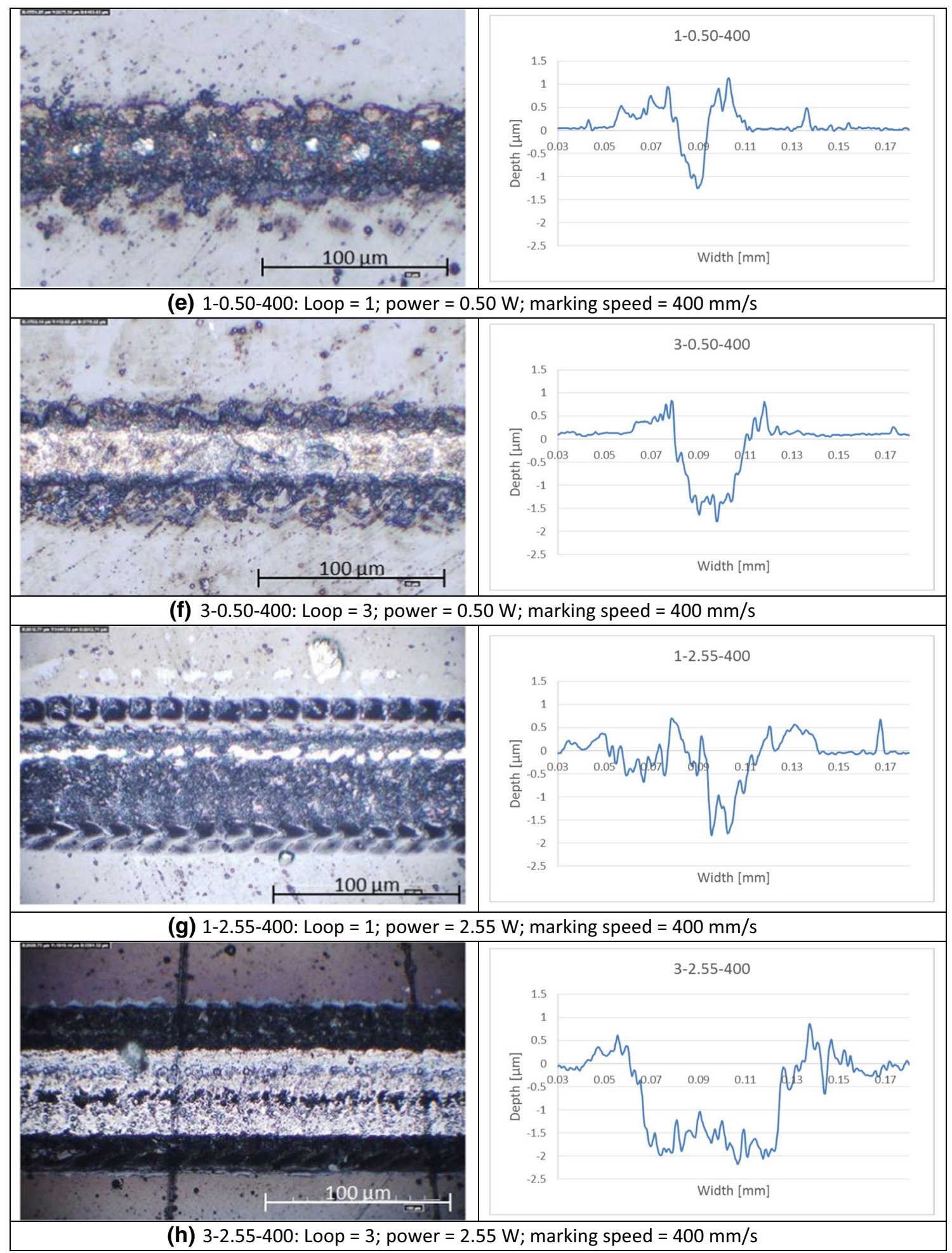

Fig. 2 (continued)

investigated, with the exception of the laser power and marking speed. These results are coherent with the physics of the process. In fact, the interaction between power and speed is the energy that irradiates to the surface, which certainly affects the track depth. Figure $3 \mathrm{c}$ shows a decreasing trend of the track depth as a function of the marking speed, while an increasing trend of the track depth as a function of the laser power and loop cycle is reported in Fig. $3 \mathrm{~b}$ and d. 
Table 8 Track geometry data

\begin{tabular}{|c|c|c|c|c|c|c|c|c|}
\hline \multirow{2}{*}{$\begin{array}{l}\text { Marking } \\
\text { speed }[\mathrm{mm} / \mathrm{s}]\end{array}$} & \multirow[t]{2}{*}{ Power [W] } & \multirow[t]{2}{*}{ Loop } & \multirow[t]{2}{*}{$E_{\mathrm{p}}[\mathrm{mJ}]$} & \multirow[t]{2}{*}{$E_{\mathrm{tot}}[\mathrm{mJ}]$} & \multicolumn{3}{|c|}{ Depth $[\mu \mathrm{m}]$} & \multirow[t]{2}{*}{ Width $[\mu \mathrm{m}]$} \\
\hline & & & & & Max & $\mu$ & $\sigma$ & \\
\hline 100 & 0.50 & 1 & 0.500 & 0.500 & 1.88 & 1.36 & 0.268 & 24 \\
\hline 100 & 0.50 & 3 & 0.500 & 1.500 & 2.17 & 1.63 & 0.306 & 31 \\
\hline 100 & 2.25 & 1 & 2.250 & 2.250 & 2.44 & 1.63 & 0.324 & 62 \\
\hline 100 & 2.25 & 3 & 2.250 & 6.750 & 2.07 & 1.70 & 0.207 & 70 \\
\hline 400 & 0.50 & 1 & 0.125 & 0.125 & 1.25 & 1.15 & 0.089 & 15 \\
\hline 400 & 0.50 & 3 & 0.125 & 0.375 & 1.79 & 1.36 & 0.153 & 32 \\
\hline 400 & 2.25 & 1 & 0.563 & 0.563 & 1.78 & 1.44 & 0.264 & 56 \\
\hline 400 & 2.25 & 3 & 0.563 & 1.690 & 2.17 & 1.67 & 0.249 & 74 \\
\hline
\end{tabular}

\begin{tabular}{|l|l|}
\hline Source & $P$ Values \\
\hline Loop & 0.001 \\
\hline Power & 0.051 \\
\hline Marking Speed & $<0.001$ \\
\hline Loop $\times$ Power & 0.941 \\
\hline Loop $\times$ Marking Speed & 0.919 \\
\hline Power $\times$ Marking Speed & 0.045 \\
\hline Loop $\times$ Power $\times$ Marking Speed & 0.072 \\
\hline
\end{tabular}

a

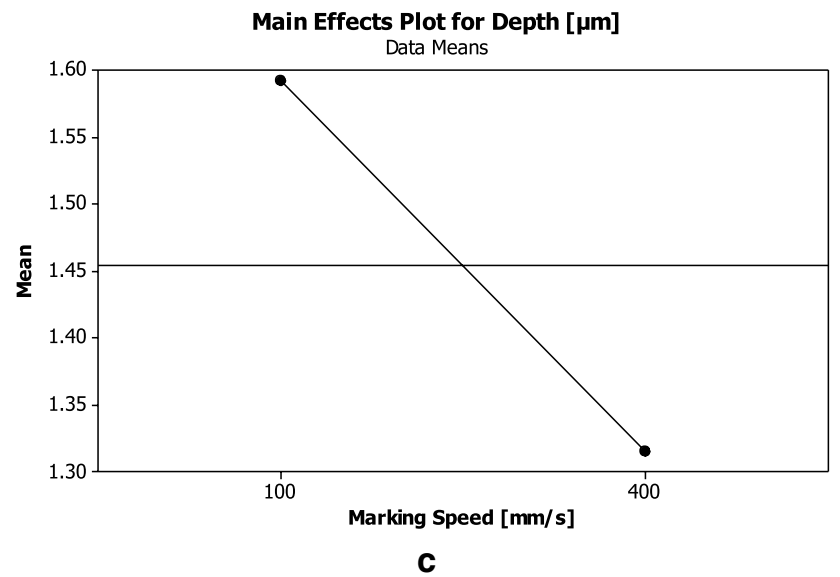

Fig. 3 Main results of the ANOVA test

Based on the ANOVA results, the authors designed a second campaign to optimize the laser texturing process. In particular, the authors further investigated how the effect of marking speed, as reported in Fig. 3a and c, significantly affects the track depth. To avoid a texture depth higher than that of the DLC layer, the authors fixed the laser power and loop cycle to $0.5 \mathrm{~W}$ and 1 , respectively. The second experimental campaign was designed by considering the intermediate values of the marking speed, from 100 to $400 \mathrm{~mm} / \mathrm{s}$.
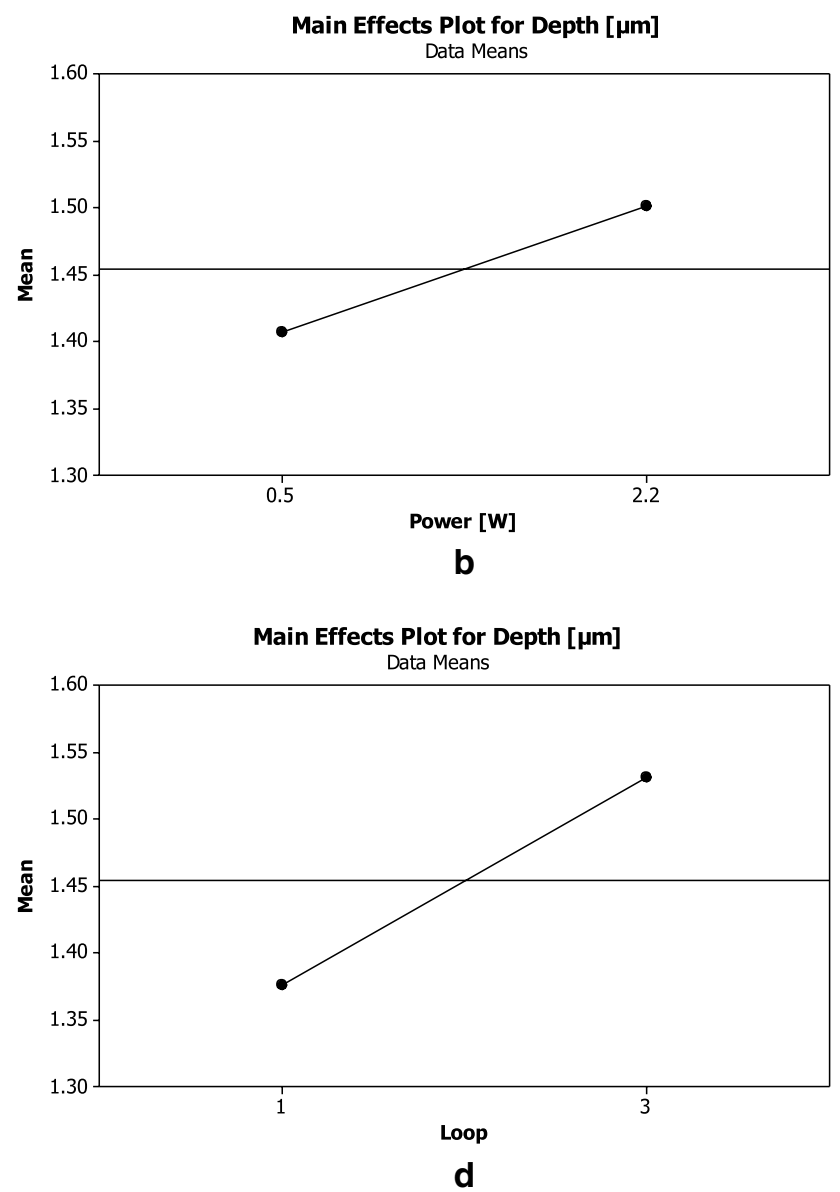

Figure 4 shows the main results of the second experimental campaign that were obtained using an optical microscope and a laser probe system.

As can be observed in Fig. 4, the plasma shielding effect does not occur for marking speed values higher than $200 \mathrm{~mm} / \mathrm{s}$. The laser track shape is similar in all the experiments, while the track depth decreases as the speed increases. Figure 5a shows a linear decreasing trend of the average track depth as the marking speed increases; however, 


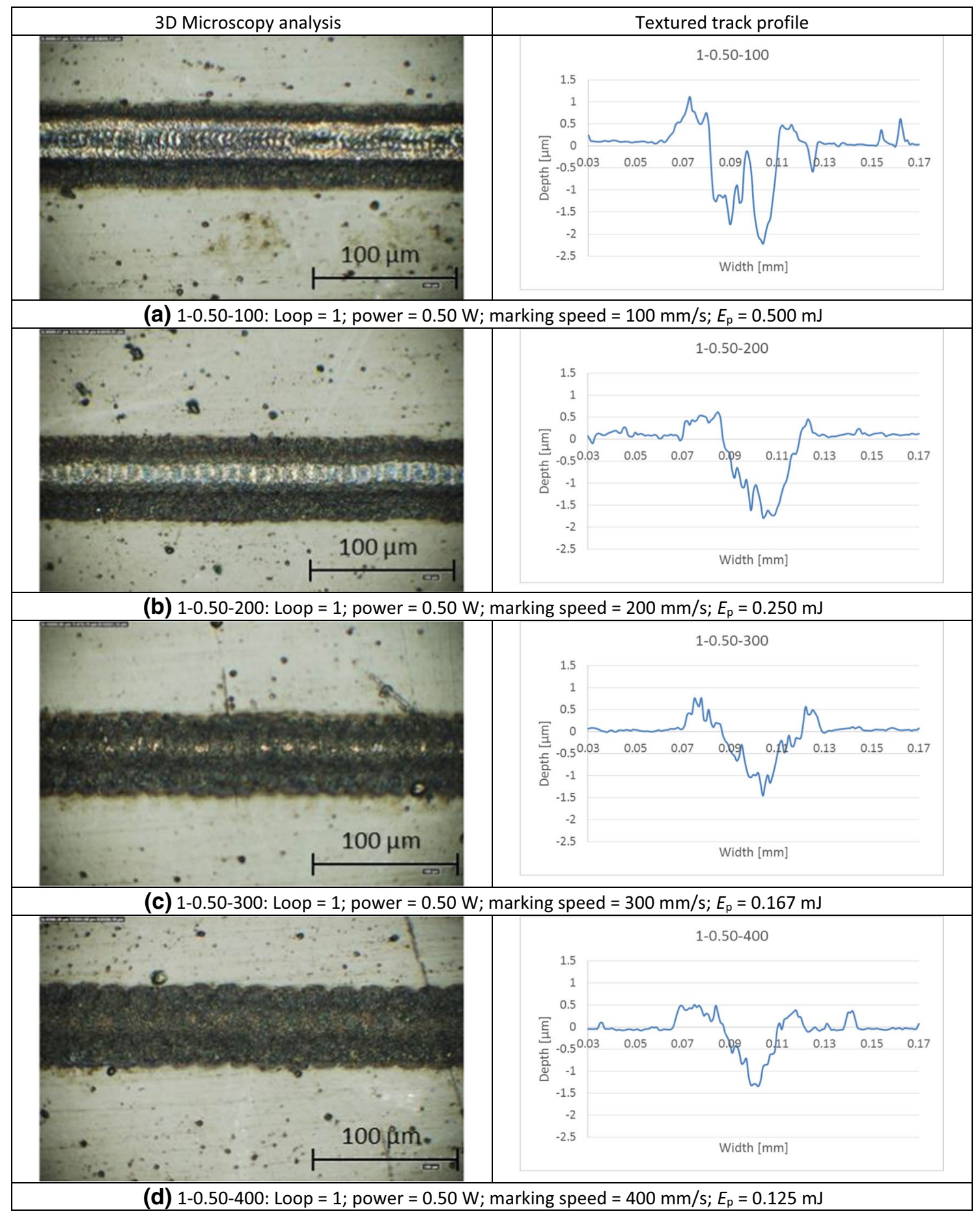

Fig. 4 Main results of the second experimental campaign

no significant effect of this parameter on the bottom surface quality is registered. Comparing these results with those of the first experimental campaign, one can see that they are in good agreement only at the high marking speed imposed. In fact, a decrease in the marking speed facilitated the uncontrolled phenomenon of the plasma plume, causing a nonreproducible modification of the track morphology. To analyze the results of the second experimental campaign, the authors performed an ANOVA statistical test. The result confirmed the effect of the marking speed $(P<0.005)$. Furthermore, Tukey's range test, with a familywise error rate equal to 5\%, was performed. As indicated in Fig. 5b, the 


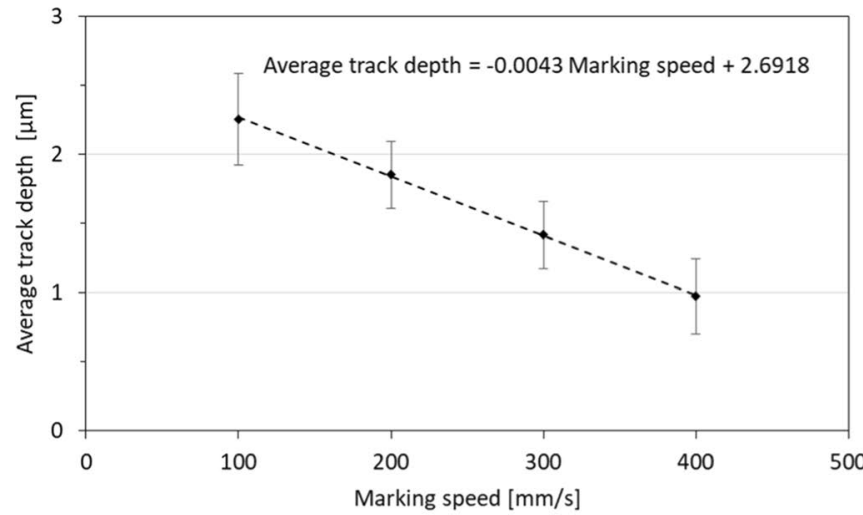

a

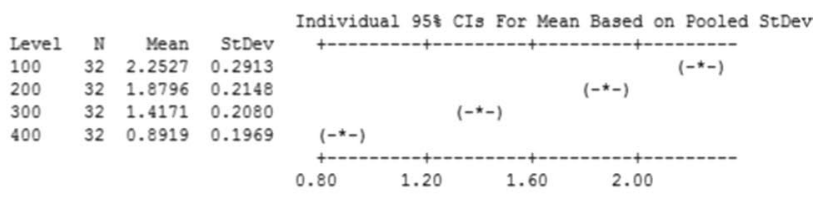

b

Fig. 5 Average track depth measured (a) and Tukey's range test results (b)

Fig. 6 Results of the SEM analyses of the as-deposited DLC (a) and textured DLC (grid line spacing of $0.25 \mathrm{~mm})(\mathbf{b})$

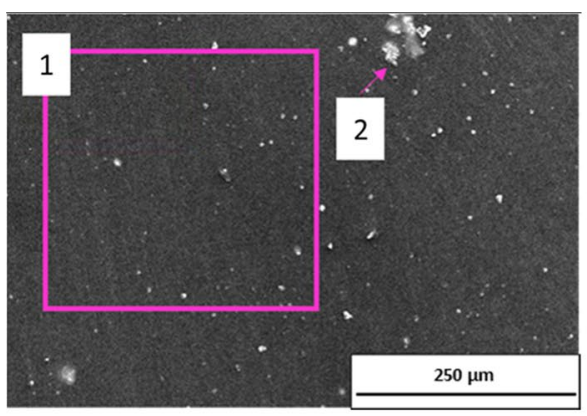

a

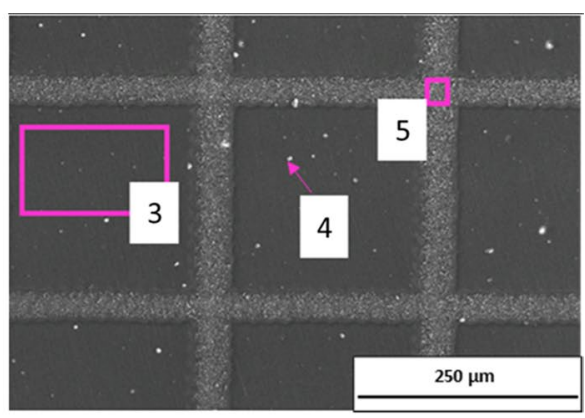

b result verifies that all the marking speed values tested are significantly different from each other.

Observing the textured track profile measurements performed on the second experimental campaign, one could assert that both the 1-0.5-300 and the 1-0.5-400 test condition matched the target imposed. In fact, the average depth was less than $1.5 \mu \mathrm{m}$. However, considering not only the average depth but also the standard deviation, the authors selected the 1-0.5-400 test condition for the micro-grid tribological characterization.

\subsection{Micro-Grid Tribological Characterization Results}

Considering the most severe condition for the textured coatings is the one with the lower grid line spacing, the mechanical (nanohardness and adhesion) characterization were carried out on the $0.25 \mathrm{~mm}$ grid spacing. On the other hand, the wear tests were performed on the three conditions to study the effect of the grid spacing on the tribological behavior.

Figure 6 shows an example of the results of the SEM-EDS analyses carried out on the top surface of the textured samples, as compared with the as-deposited samples. As can be seen in the figure, droplets and small cavities are present in both the as-deposited (Fig. 6a) and the textured
Table 9 EDS results of the coating morphology analysis (wt.\%)

\begin{tabular}{lllll}
\hline Spectrum & $\mathrm{C}$ & $\mathrm{Si}$ & $\mathrm{Cr}$ & $\mathrm{Fe}$ \\
\hline 1 & 70.14 & 15.05 & 14.10 & 0.71 \\
2 & 70.92 & 15.05 & 14.03 & \\
3 & 71.09 & 14.96 & 13.95 & \\
4 & 59.84 & 19.63 & 18.67 & 1.86 \\
5 & 57.77 & 18.94 & 22.59 & 0.70 \\
\hline
\end{tabular}

samples (Fig. 6b). On the textured surface, no connection among the defects exists and the laser texture was identified (spectrum 2 vs. spectrum 4). In particular, the droplets are strictly connected to the PACVD process, and they could induce problems in terms of corrosion resistance and surface roughness [4-6]. The EDS analysis (Table 9), which was performed far away from the laser texture (spectrum 3), showed a chromium and iron percentage comparable with the measurements performed on the as-deposited surface (spectrum 1). Therefore, no changes in the chemical composition were observed far away from the texture. Furthermore, some analyses were carried out to verify that the laser pattern did not expose the substrate in correspondence to groove overlays. As can be seen in the figure, the chromium 
and iron content confirms that the thickness of the removed layer is smaller than the DLC thickness (spectrum 5), and is comparable with the change in the chemical composition measured on deposition defects (spectrum 4).

The cross-section microstructure was analyzed using a scanning electron microscope to investigate in more detail the potential presence of discontinuities such as cracks or other defects caused by the texturing process at the substrate-coating interface. The cross sections reported in Fig. 7a show a DLC layer with a uniform thickness and the interlayers. The results of the cross-section SEM analyses of the textured DLC reported in Fig. 7b show no evidence of cracks or delaminations. It is also possible to conclude that no damage related to the laser ablation process was created in the textured condition.

The nanoindentation and adhesion test results are reported in Fig. 8. The coating hardness was not considerably affected by the texture presence. However, the standard deviation value increased from the as-deposited to the textured surface, probably because of a more irregular contact between the surface and the indenter related to the textured presence.

The adhesion test results showed similar first and second critical loads for the as-deposited and textured samples. On the other hand, LC3 referring to the full coating delamination was significantly different between the textured and the untextured samples. In particular, LC3 values were higher and had a wider standard deviation for the textured surface. An interpretation of these results is that they are related to the scratch orientation with respect to the laser texture. As a scratch was randomly performed on the surface of the samples, each scratch obtained different coating thicknesses at the same critical load. Therefore, a full detachment of the coating from the substrate could occur at different load levels. This effect was not present for the as-deposited samples as the DLC thickness was constant on the tested surface. After the coating characterization, wear tests were performed. Figure 9 reports the coefficient-of-friction (COF) variation as a function of the sliding distance and the grid spacing. As can be seen in the figure, there is an initial decrease in the COF in both the as-deposited and the textured surfaces. No significant differences due to the presence of the textures can be observed, independently from the laser grid spacing.

3D microscopy analyses of the wear tracks were carried out at the end of the tribological tests (Fig. 10). As shown in Fig. 10, no severe signs of abrasion are present on all surfaces. However, the wear track width is strongly reduced in the case of the textured coating from 118 to $81.21 \mu \mathrm{m}$, achieving a $30 \%$ reduction.
Fig. 7 Cross section of the asdeposited DLC (a) and textured DLC (grid line spacing of $1 \mathrm{~mm})(\mathbf{b})$

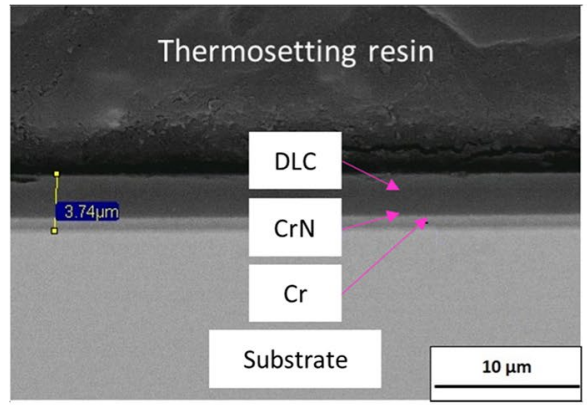

a

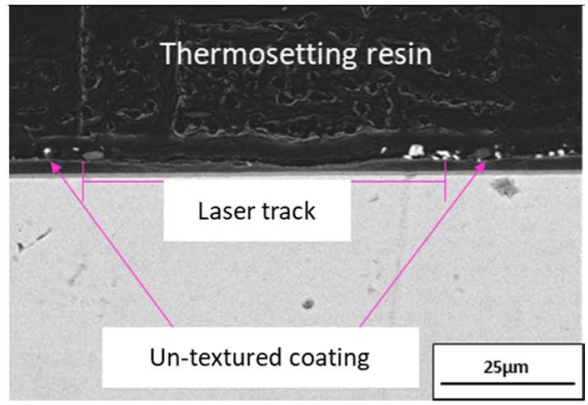

b

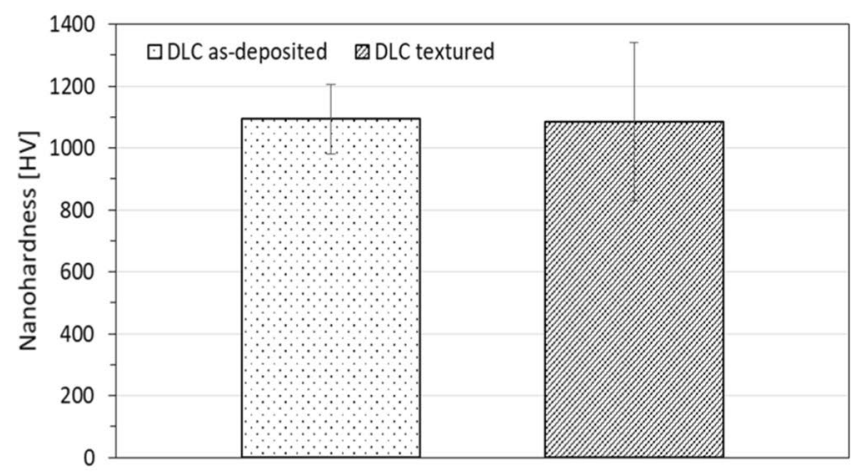

a

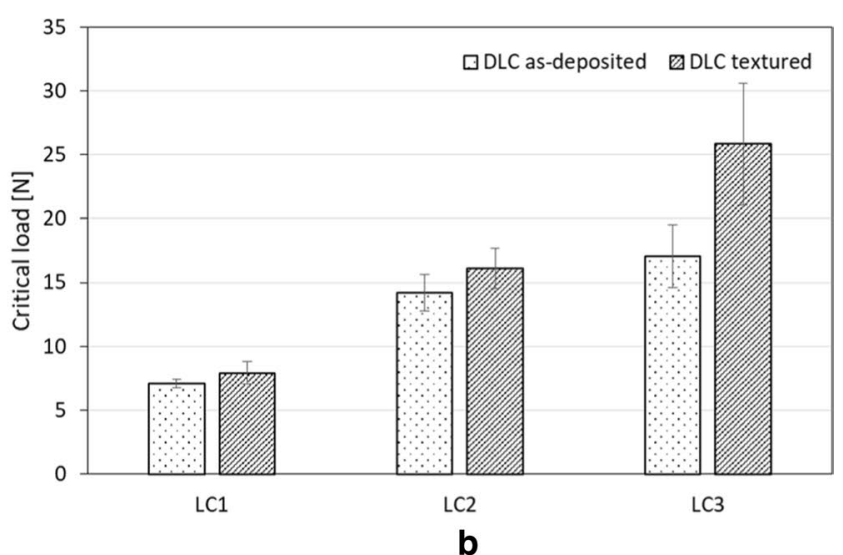

b

Fig. 8 Results of the nanohardness (a) and adhesion tests (b) 


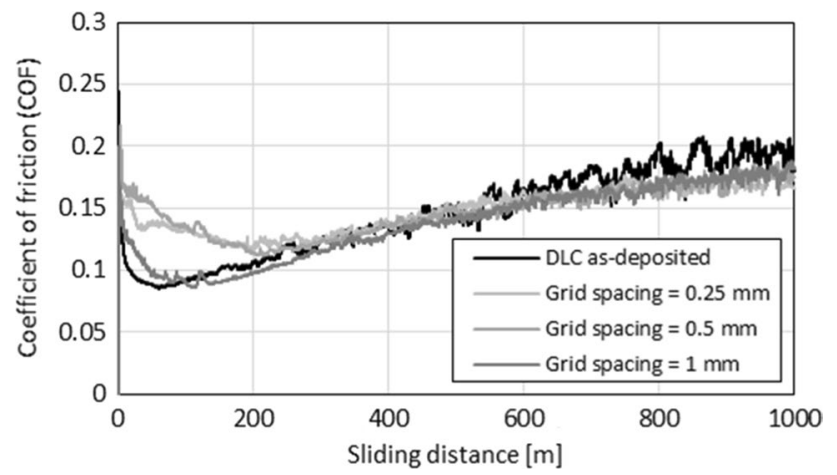

Fig. 9 Coefficient of friction as a function of the sliding distance

Figure 11a resumes the main results obtained; in particular is possible to observe that the pattern lead to a wear improvement but until a limit. As can be noticed in Figs. 10d and $11 \mathrm{a}$ when the spacing became under $0.5 \mathrm{~mm}$ the unlasered surface in contact with the alumina sphere decreases; this phenomena are probably related to an increase of contact pressure and a wider wear track is generated. Figure $11 \mathrm{~b}$ confirm with a statistical approach that the $1 \mathrm{~mm}$ and $0.5 \mathrm{~mm}$ texture lead to an improvement of thewear resistance with an opposite behavior for $0.25 \mathrm{~mm}$ texture.

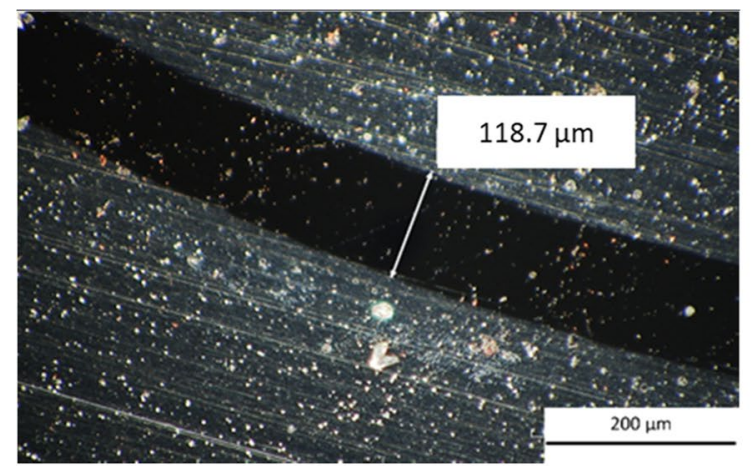

a

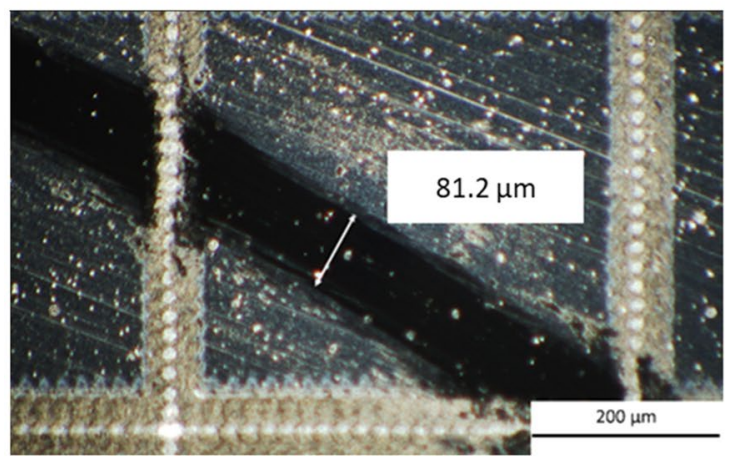

C

\section{Conclusions}

The present work investigated the effectiveness of selected laser process parameters, such as power, marking speed, and loop cycle, to realize a texture on a thin DLC coating. In particular, this work was focused on the possibility of realizing micro-grids on a thin DLC coating $(1.5 \mu \mathrm{m})$. Analyses of the morphological and mechanical properties (such as nanohardness, adhesion, and wear resistance) were performed to study the effect of the realized texture. The obtained results showed that all the laser process parameters investigated affected the laser track morphology in terms of bottom track quality, track depth, and width. The following key observations are reported:

(1) All the laser process parameters studied affected the laser track depth and width. Moreover, the authors measured a decreasing trend of the track depth as a function of the marking speed, while an increasing trend of the track depth as a function of the laser power and loop was measured. The authors further investigated the effect of marking speed and identified a range of values suitable to avoid the plasma shielding effect, which can produce an uncontrolled texture geometry.

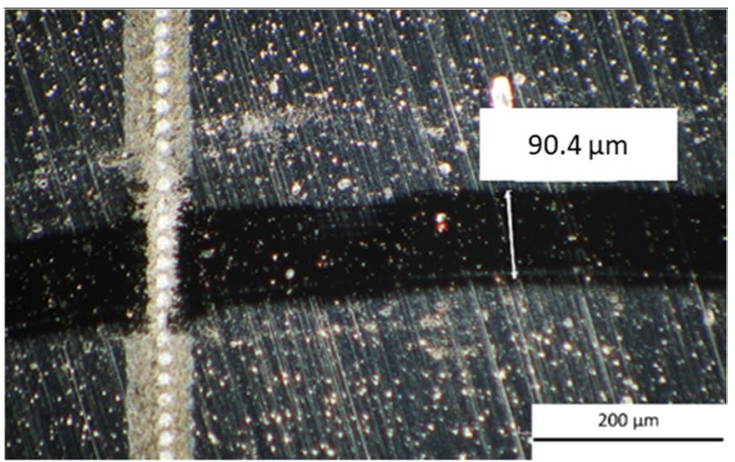

b

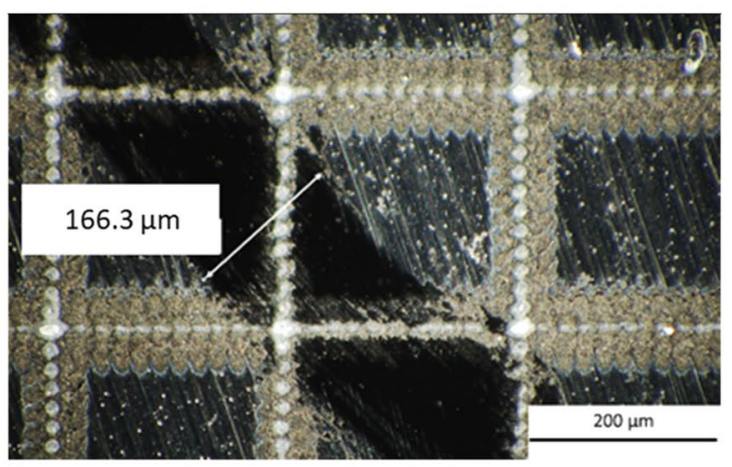

d

Fig. 10 Top view of the wear tracks of the as-deposited DLC (a) and $1 \mathrm{~mm}$ textured DLC (b) $0.5 \mathrm{~mm}$ textured track (c), $0.25 \mathrm{~mm}$ textured track (d) 


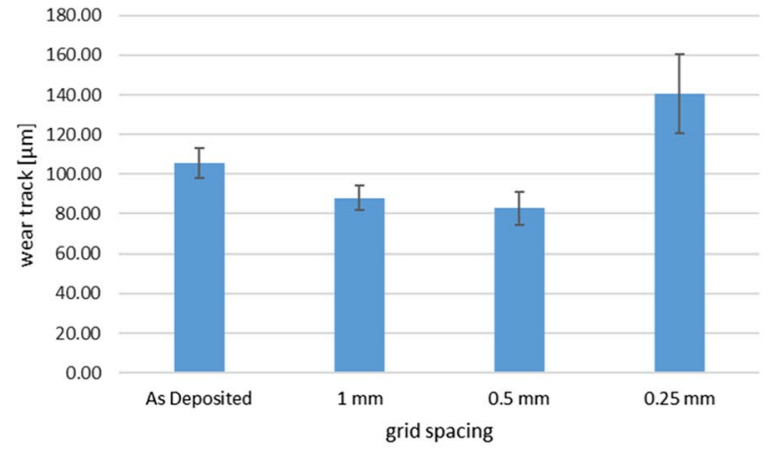

a

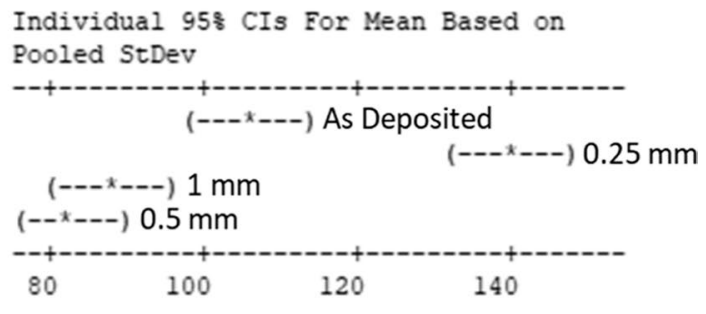

b

Fig. 11 Average wear track measured (a) and Tukey's range test results (b)

(2) The coating characterization in terms of nanohardness and adhesion revealed that the laser texture did not considerably affect the coating properties investigated. In particular, LC3 in the textured sample increased.

(3) The results of the wear tests showed positive and negative effect of the laser texture. More in detail, the textured samples showed a superior tribological behavior and a reduced track width $(30 \%)$ after the wear tests compared with the untextured samples for texture having grid spacing of 1 and $0.5 \mathrm{~mm}$. On the contrary when the spacing texture became lower the wear performance decreases.

\footnotetext{
Acknowledgements The authors are gratefully indebted to D. Romagnoli of STS s.r.l.-Cellatica (Brescia) for the coating deposition, Simitecno s.r.l.-Frascati (Roma) for the measurements of the textured track profiles, A. Ghidini of Lucchini RS-Lovere (Bergamo) for the steel supply and Maria Surfaro for his contribution in the first experimental campaign. The authors would like to mention that the present work has been carried out in the framework of the AITeM-PromozioneL@ser association.
}

Funding Open access funding provided by Università degli Studi di Brescia within the CRUI-CARE Agreement.

Open Access This article is licensed under a Creative Commons Attribution 4.0 International License, which permits use, sharing, adaptation, distribution and reproduction in any medium or format, as long as you give appropriate credit to the original author(s) and the source, provide a link to the Creative Commons licence, and indicate if changes were made. The images or other third party material in this article are included in the article's Creative Commons licence, unless indicated otherwise in a credit line to the material. If material is not included in the article's Creative Commons licence and your intended use is not permitted by statutory regulation or exceeds the permitted use, you will need to obtain permission directly from the copyright holder. To view a copy of this licence, visit http://creativecommons.org/licenses/by/4.0/.

\section{References}

1. Grill, A. (1999). Diamond-like carbon: State of the art. Diamond and Related Materials, 8, 428-434.

2. Robertson, J. (2002). Diamond-like amorphous carbon. Materials Science and Engineering R, 37, 129-281.

3. Hauert, R. (2004). An overview on the tribological behavior of diamond-like carbon in technical and medical applications. Tribology International, 37, 991-1003.

4. Zhang, T. F., Jiang, F., Liao, T. T., Deng, Q. Y., Li, S. S., Wang, Y., \& Leng, Y. X. (2016). Tribological behavior of diamond-like carbon film sliding against $\mathrm{CoCrMo}$ or $\mathrm{Al} 2 \mathrm{O} 3$ in air and water environment. Tribology International, 95, 456-461.

5. Liu, Y., Erdemir, A., \& Meletis, E. I. (1996). A study of the wear mechanism of diamond-like carbon films. Surface and Coatings Technology, 82, 48-56.

6. Dufils, J., Faverjon, F., Héau, C., Donnet, C., Benayoun, S., \& Valette, S. (2017). Evaluation of a variety of a-C: H coatings on PEEK for biomedical implants. Surface and Coating Technology, 313, 96-106.

7. Kalin, M., \& Vizintin, J. (2006). Differences in the tribological mechanisms when using non-doped, metal doped ( $\mathrm{Ti}, \mathrm{WC})$, and non-metal-doped $(\mathrm{Si})$ diamond-like carbon against steel under boundary lubrication, with and without oil additives. Thin Solid Films, 515, 2734-2747.

8. Ikeyama, M., Nakao, S., Miyagawa, Y., \& Miyagawa, S. (2005). Effects of Si content in DLC films on their friction and wear properties. Surface and Coatings Technology, 191, 38-42.

9. Dobrenizki, L., Tremmel, S., Wartzack, S., \& Hoffman, D. C. E. A. (2016). Efficiency improvement in automobile bucket tappet/ camshaft contacts by DLC coatings - Influence of engine oil, temperature and camshaft speed. Surface and Coatings Technology, 308, 360-373.

10. Onate, J. I., Comin, M., Braceras, I., Garcia, A., Viviente, J. L., Brizuela, M., Garagorri, N., Peris, J. L., \& Alava, J. I. (2001). Wear reduction effect on ultra-high-molecular-weight-polyethylene by application of hard coatings and ion implantation on cobalt chromium alloy, as measured in a knee wear simulation machine. Surface and Coatings Technology, 142-144, 1056-1062.

11. Khatir, S., Hirose, A., \& Xiao, C. (2014). Coating diamond-like carbon films on polymer substrates by inductively coupled plasma assisted sputtering. Surface and Coatings Technology, 253, 96-99.

12. Ahmed Obeidi, M., McCarthy, E., \& Brabazon, D. (2016). Methodology of laser processing for precise control of surface microtopology. Surface and Coating Technology, 307, 702-712. 
13. Etsion, I. (2005). State of the art in laser surface texturing. Journal of Tribology, 127(1), 248-253.

14. Wu, Z., Xing, Y., Huang, P., \& Liu, L. (2017). Tribological properties of dimple-textured titanium alloys under dry sliding contact. Surface and Coatings Technology, 309, 21-28.

15. Tang, W., Zhou, Y., Zhu, H., \& Yang, H. (2013). The effect of surface texturing in reducing the friction and wear of steel under lubricated sliding conditions. Applied Surface Science, 273, 199-204.

16. Amanov, A., Watabe, T., Tsuboi, R., \& Sasaki, S. (2013). Improvement in the tribological characteristics of Si-DLC coating by laser surface texturing under oil-lubricated point contacts at various temperatures. Surface and Coatings Technology, 232, 549-560.

17. Shum, P. W., Zhou, Z. F., \& Li, K. Y. (2014). To increase the hydrophobicity, non-stickiness and wear resistance of DLC surface by surface texturing using a laser ablation process. Tribology International, 78, 1-6.

18. Dufils, J., Faverjon, F., Héau, C., Donnet, C., Benayoun, S., \& Valette, S. (2017). Combination of laser surface texturing and DLC coating on PEEK for enhanced tribological properties. Surface \& Coatings Technology, 329, 29-41.

19. Koszela, W., Pawlus, P., Reizer, R., \& Liskiewicz, T. (2018). The combined effect of surface texturing and DLC coating on the functional properties of internal combustion engines. Tribology International, 127, 470-477.

20. Shum, P. W., Zhou, Z. F., \& Li, K. Y. (2013). Investigation of the tribological properties of the different textured DLC coatings under reciprocating lubricated conditions. Tribology International, 65, 259-264.

21. Arslan, A., Masjuki, H. H., Kalam, M. A., Varman, M., Mosarof, M. H., Mufti, R. A., Quazi, M. M., Khuong, L. S., Liaqat, M., Jamshaid, M., Alabdulkarem, A., \& Khurram, M. (2017). Investigation of laser texture density and diameter on the tribological behavior of hydrogenated DLC coating with line contact configuration. Surface and Coatings Technology, 322, 31-37.

22. Liu, X., Zhang, W., \& Sun, G. (2019). The influence of textured interface on DLC films prepared by vacuum arc. Surface and Coatings Technology, 365, 143-151.

23. He, D., Zheng, S., Pu, J., Zhang, G., \& Hu, L. (2015). Improving tribological properties of titanium alloys by combining laser surface texturing and diamond-like carbon film. Tribology International, 82, 20-27.

24. Lu, L., Zhang, Z., Guan, Y., \& Zheng, H. (2018). Comparison of the effect of typical patterns on friction and wear properties of chromium alloy prepared by laser surface texturing. Optics and Laser Technology, 106, 272-279.

Publisher's Note Springer Nature remains neutral with regard to jurisdictional claims in published maps and institutional affiliations.

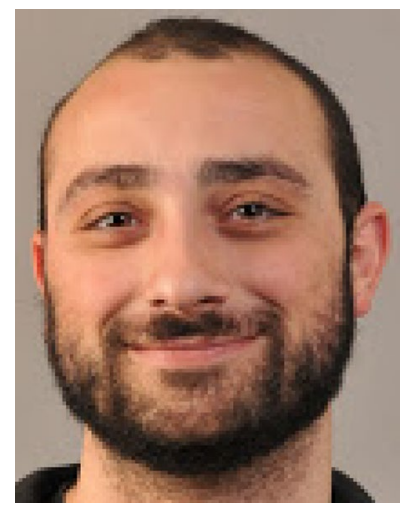

L. Giorleo Associate Professor at the Mechanical and Industrial Department of University of Brescia. His research focuses mainly on the plastic deformation process (ring rolling); micromachining (microdrilling, laser ablation and laser polishing) and on design for additive manufacturing methods.

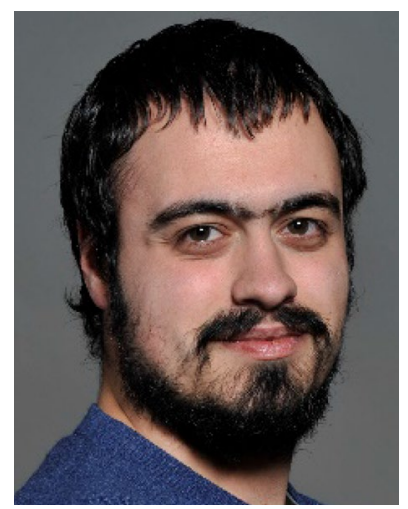

L. Montesano Laboratory technician of metallurgy group at university of Brescia. His research interest are thin films, corrosion and wear damage mechanism as well as light alloys and innovative foundry process. He has published 36 peer-reviewed papers.

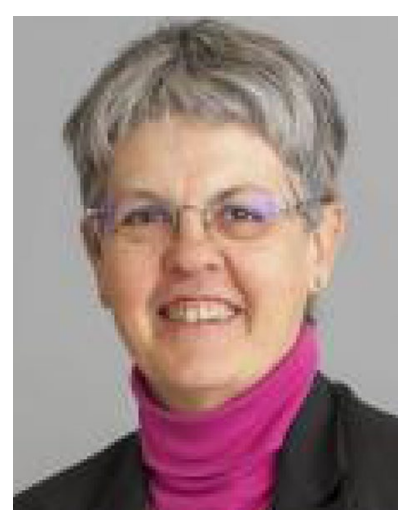

G. M. La Vecchia Full professor of Metallurgy at University of Brescia. Her research interests are: microstructural and mechanical characterization of metallic alloys; functional coatings to improve wear and corrosion resistance. She has published over 150 peer-reviewed papers. 